\title{
YAG Laser Versus Ultrasound Assisted Liposuction in the Management of Grade II Gynecomastia (Comparative Study)
}

\author{
HANY S. SETTA, M.D.; KHALED A. REYAD, M.D. and NIVEEN F. AL-MAHMOUDY, M.D. \\ The Department of Plastic, Burn and Maxillofacial Surgery, Faculty of Medicine, Ain Shams University, Cairo, Egypt
}

\begin{abstract}
Introduction: Gynecomastia is a common condition encountered nowadays. Many surgical treatment options are available yet the best modality is still controversial. ND: YAG laser assisted and ultrasound (VASER) assisted liposuction are well defined and respected tools for liposuction yet no one proved to be superior over the other. This study's proposal is to compare the post-operative results for patients treated with both modalities concerning the complications and patient satisfaction.

Patients and Methods: Patients with gynecomastia (grade 2) were randomly divided to ND: YAG laser liposuction (group 1) and ultrasound assisted (VASER) liposuction (group 2), where liposuction zones were marked in all patients. Complications and satisfaction scores were recorded and statistically analyzed.
\end{abstract}

Results: Twenty patients were in this study; 10 in each group. The median satisfaction score for laser assisted group was 4.5 while for ultrasound group was 3.4.

Conclusion: Both ND: YAG laser and VASER are powerful tools in management of gynecomastia (grade 2) with more satisfaction and less complications in the laser group.

Keywords: Gynecomastia - ND - YAG laser - VASER.

\section{INTRODUCTION}

Gynecomastia is defined as a benign enlargement of male breasts with an incidence of $36 \%$ that may be unilateral or bilateral [1]. This medical and cosmetic condition has many known causes including medications intake, metabolic disorders, adrenal and testicular tumors, primary and secondary hypogonadism, hyperthyroidism, and renal diseases although most cases are idiopathic [2,3]. Gynecomastia can be a source of significant embarrassment especially in younger males.

Simon's [4] classification is one of the valid description of the gynecomastia grades as it describes the deformity from surgical point of view, other classifications were proposed for grading and hence the management accordingly $[5,6]$.

Gynecomastia surgical treatment is one of the most commonly performed plastic surgery procedures on men [7]. It should be individualized according to the patient's needs and expectations. The treatment of gynecomastia depends on multiple factors, and the best modality is controversial [8]. The surgical management has grown substantially over the last 60 years $[\mathbf{9 , 1 0}$. The proposed treatments entail regaining of normal breast aesthetics in form of restoration of the male chest shape with good contour, elimination of the infra-mammary fold, correction of nipple areola complex position, removal of redundant skin, equality of both sides [6]. Male breast has four distinct zones those areas should be targeted incrementally to avoid postoperative patient dissatisfaction [11].

Among the different modalities, concerning the management of gynecomastia fat component other than traditional liposuction are ND: YAG laser [12] and ultrasound (VASER) assisted liposuction [13]. In this study the proposal is to compare between ND: YAG laser and ultrasound (VASER) assisted liposuction techniques with surgical excision of glandular tissue concerning the post-operative results in form of patient satisfaction and incidence of complications.

\section{PATIENTS AND METHODS}

This retrospective study was done in Ain Shams University Hospitals during the period from January 2016 to December 2018 on patients with gynecomastia grade II $_{\mathrm{A}, \mathrm{B}}$ (Simon's staging) with excess fat, glandular tissue \pm skin excess. All patients had a well informed consent. Pre-operative evaluation was done, in the form of medical history, general 
and local examination, routine laboratory and endocrinal assessment to exclude cases with secondary gynaecomastia, and only the idiopathic cases were included in this study. Standard pre and post-operative photographs were taken.

All patients were marked pre-operatively in a standing position. Anteriorly, inter pectoral groove and the lateral and inferior border of pectoralis muscle were marked during muscle contraction. After that, in lateral position, the anterior border of the latissimus dorsi muscle and the space between the latissimus dorsi and pectoral muscle lying on the lateral chest wall were marked.

The area for liposuction was divided into four zones Fig. (1); I- Between lower border of pectoralis and IMF, II- Between anterior and posterior axillary folds, III- Over pectoralis muscle, IVInterpectoral region down to linea alba.

The operation was done under general anesthesia, where the patient was lying in supine position with both arms extended at 90 degrees. After sterilization and draping, infiltration of tumescent 1:500,000 adrenaline and saline solution was done by blunt small caliber infiltration cannula. The patients were randomly divided into two groups:

A- ND: YAG laser liposuction group: Liposuction was done with the aid of laser assisted liposuction (ND: YAG laser 1064-nm wave length) (Fotona XP2, Solovania) at a power of $15 \mathrm{~W}$ with continuous emission, a repetition rate of $40 \mathrm{~Hz}$, and $8-12 \mathrm{~kJ}$ total average accumulated energy per breast. The endpoints of laser procedure were tactile warmth and ease of cannula advancement during the procedures.

B- Ultrasound assisted liposuction was done with the aid of ultrasound assisted liposuction (VASER-LySonix 3000 Ultrasonic Surgical Aspirator System (Byron Medical, Tucson, Ariz.), set on the pulse mode at amplitude of 80 percent. A plastic port is placed into the incision through which the ultrasound probe is passed. The endpoint for ultrasound application is loss of tissue resistance throughout the marked area (approximately 4 to 10 minutes per side).

Fat Aspiration was done by liposuction blunt $4 \mathrm{~mm}$ cannula with semi-circular areolar incision for glandular excision in both groups. Disruption of the inframammary fold was done in order to fade the adherence zone between breast and chest wall. An elastic compression garment was applied for six to eight weeks postoperatively.

Results, complications and other further interventions were recorded and analyzed statistically. Statistical analysis was done by IBM computer using SPSS (statistical program for social science Version 12). The $p$-value was calculated and correlated to the variants and $p$-value was considered insignificant if $>0.05$, significant if $<0.05$ and highly significant if $<0.01$.

\section{RESULTS}

Twenty patients $(n=20)$ were included in the study, age was ranging from 25-45 years (average 31 ). All patients underwent liposuction (10 cases with ND: YAG laser and 10 cases with ultrasound assisted liposuction) and glandular excision with semicircular areolar incision.

All patients were followed-up for one year and were evaluated by Breast Evaluation Questionnaire (BEQ) [14] to measure patient satisfaction, the patients were asked to respond to all questions using a 5 -point scale $(1=$ very dissatisfied; $2=$ dissatisfied; $3=$ neither; $4=$ satisfied; $5=$ very satisfied). The questionnaire assesses the degree of comfort with breast size in different life situations, the degree of comfort with appearance either dressed or undressed, the patient's psychological satisfaction for himself and his life partner; and the degree of satisfaction about numbness, symmetry and scars.

Tables $(1,2)$ summarizes the results of the satisfaction score. The median for laser assisted group was 4.5 while for ultrasound group was 3.4 Figs. $(1,2)$.

Table (1): Breast Evaluation Questionnaire (BEQ) satisfaction in ND: YAG laser group.

\begin{tabular}{lllllllllll}
\hline Case No. & 1 & 2 & 3 & 4 & 5 & 6 & 7 & 8 & 9 & 10 \\
\hline $\begin{array}{l}6 \text { months post-laser } \\
\text { assisted liposuction }\end{array}$ & 4 & 5 & 4 & 4 & 5 & 4 & 5 & 5 & 5 & 4 \\
\hline
\end{tabular}

Table (2): Breast Evaluation Questionnaire (BEQ) satisfaction score in VASER group.

\begin{tabular}{lllllllllll}
\hline Case No. & 1 & 2 & 3 & 4 & 5 & 6 & 7 & 8 & 9 & 10 \\
\hline $\begin{array}{l}6 \text { months post-Ultrasound } \\
\begin{array}{l}\text { assisted liposuction } \\
\text { - }\end{array}\end{array}$ & 3 & 4 & 5 & 5 & 5 & 3 & 1 & 3 & 1 & 4 \\
\hline
\end{tabular}



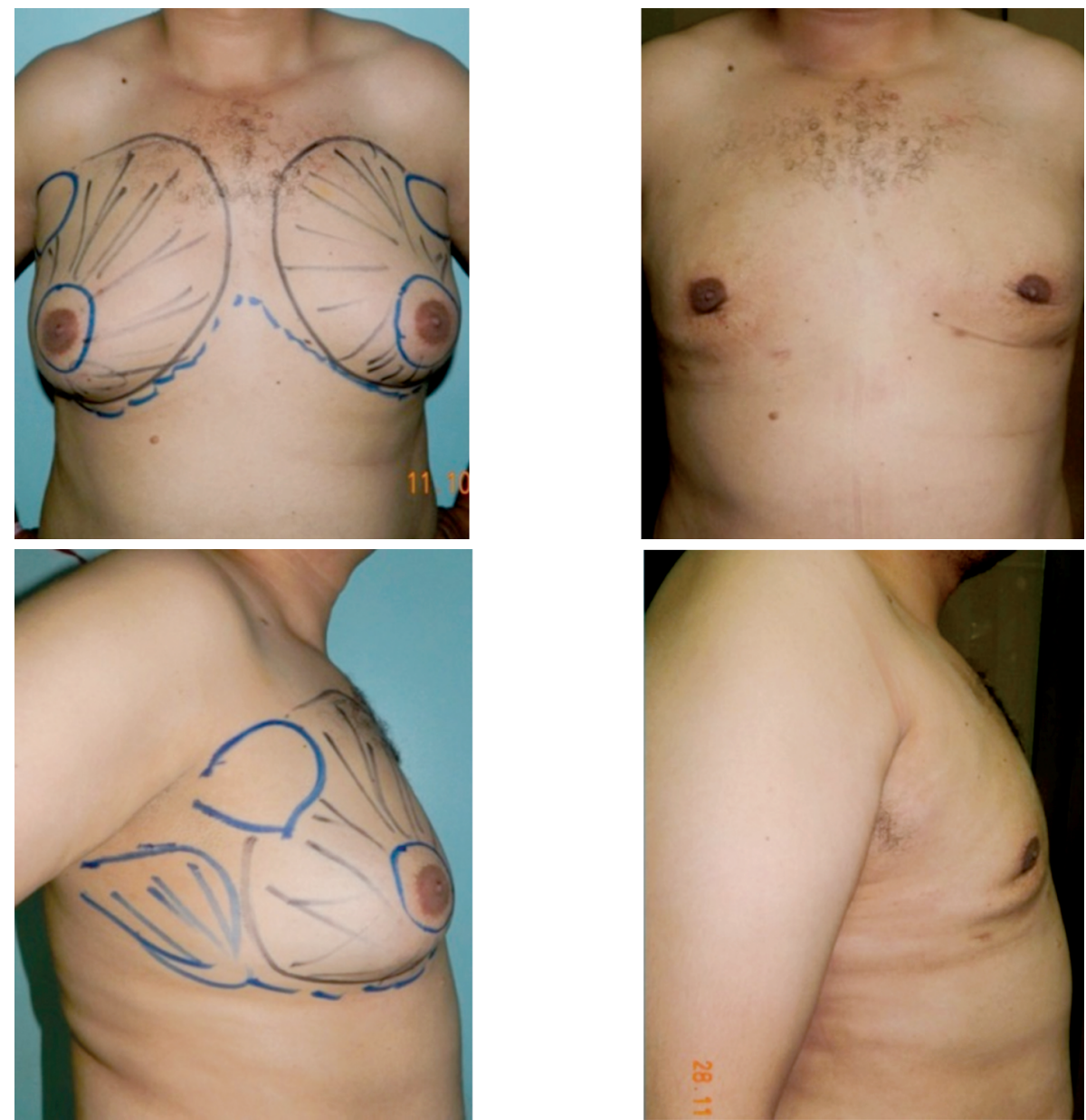

Fig. (1): (Upper) front and (lower) side pre-operative and post-operative view for patient with grade IIa gynecomastia who was operated upon using ND: YAG laser and gland excision.
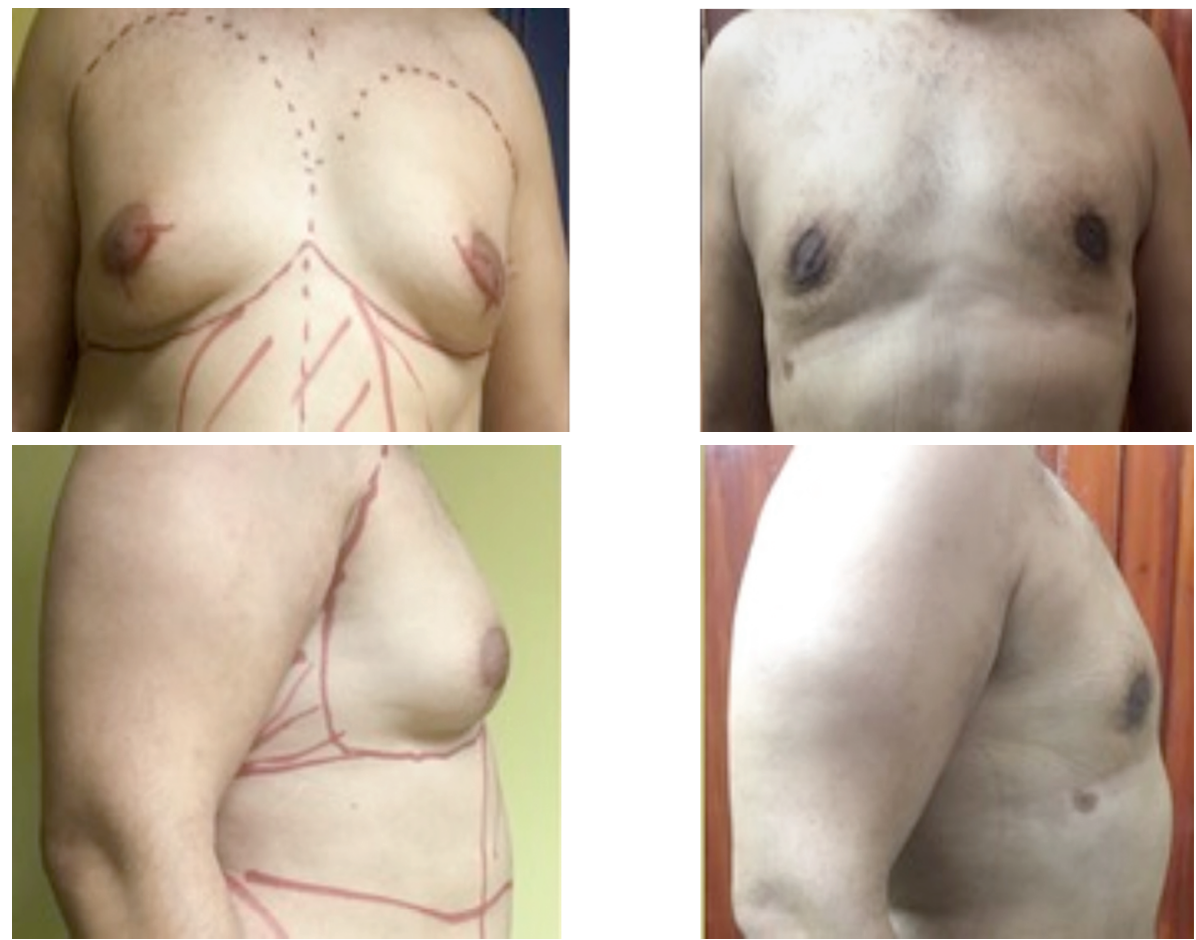

Fig. (2): (Upper) front and (lower) side pre-operative and post-operative view for patient with grade IIa gynecomastia who was operated upon using ultrasound assisted liposuction (VASER) and glandular excision. 
Concerning complications in both groups; two patients suffered from port site burn that was full thickness about one and half centimeters in the Ultrasound assisted liposuction (VASER) group while no burn occurred in the ND: YAG Laser group. Massive seroma occurred in two cases in the Ultrasound assisted liposuction (VASER) group, and in one case in the ND: YAG Laser group, all cases were managed conservatively. No other major significant complications occurred.

Some other complications were recorded which included numbness in the NAC which happened in three cases in the ND: YAG Laser group and in two cases of the Ultrasound assisted liposuction (VASER) group which was managed conservatively with oral neurotonics. Asymmetry occurred in one patient in ND: YAG Laser group (one of two cases of massive seroma) (Tables 3,4).

Post-operative pain scoring was assessed in both groups with no statistical significance. Postoperative edema time was recorded in both groups with faster resolving of edema in ND: YAG laser group but with no statistical significance compared to the Ultrasound assisted liposuction (VASER) group.

Table (3): Complications occurred in ND: YAG laser liposuction group.

\begin{tabular}{lccccccccc}
\hline Case No., & 1 & 2 & 3 & 4 & 5 & 6 & 7 & 8 & 9 \\
\hline ND: YAG laser liposuction group & $-\begin{array}{l}\text { Numbness } \\
\text { in NAC }\end{array}$ & - & $-\begin{array}{l}\text { Massive seroma } \\
\text { asymmetry }\end{array}$ & $-\begin{array}{l}\text { Numbness } \\
\text { in NAC }\end{array}$ & $\begin{array}{l}\text { Numbness } \\
\text { in NAC }\end{array}$ & - \\
\hline
\end{tabular}

Table (4): Complications occurred in ultrasound assisted (VASER) group.

\begin{tabular}{lrrrrrrrrr}
\hline Case No., & 1 & 2 & 3 & 4 & 5 & 6 & 7 & 8 & 9 \\
\hline $\begin{array}{l}\text { Ultrasound assisted } \\
\text { liposuction (VASER) group }\end{array}$ & - & - & $\begin{array}{l}\text { Massive } \\
\text { seroma }\end{array}$ & $\begin{array}{l}\text { Port site } \\
\text { burn }\end{array}$ & $-\begin{array}{l}\text { Numbness } \\
\text { in NAC }\end{array}$ & $\begin{array}{l}\text { Massive seroma, } \\
\text { Numbness in NAC }\end{array}$ & - & $\begin{array}{l}\text { Port site } \\
\text { burn }\end{array}$ & - \\
\hline
\end{tabular}

\section{DISCUSSION}

Gynecomastia causes considerable emotional discomfort and limits daily activity. The surgical treatment of gynecomastia significantly contributes to increased social activity, improves social acceptance and emotional comfort, and improves satisfaction with personal life $[\mathbf{1 5}, \mathbf{1 6}]$. The plenty of published gynecomastia classification systems is evidence to the fact that there is no single system that surgeons approve [17].

Liposuction is one of the most commonly performed procedures in the management of gynecomastia especially in grade I, II. As a general rule for liposuction, we applied the concept of liposuction of the negative spaces as proposed by Hoyos and Perez [18] for all cases in both groups, which ended up with a more precise and appealing results in most of the cases comparable to others surgeons following the same methodology.

Suction assisted liposuction combined with open excision was first described by Teimourian and Perlman [19], fat in gynecomastia consists of firm fibrous connective tissue and compact adipose tissues, which makes conventional liposuction more difficult to perform for that, external ultrasound-assisted lipoplasty [20], power-assisted lipo- plasty [21], interventional ultrasound-assisted liposuction [22-24] have been developed in the 1990s.

Laser-assisted lipolysis introduced by Apfelberg [25], various wavelengths have been used [26]. The $1064 \mathrm{~nm}$ wavelength demonstrates high fat absorption with less tissue penetration and scatter [12]. And in our study we preferred using this wavelength for its mentioned merits. However, the ideal wave length in laser lipolysis is still debatable [26].

In this study, regarding ND: YAG laser liposuction group, it was associated with less trauma leading to less post-operative edema, and postoperative pain, which is also comparable to previous studies [27].

In addition, laser liposuction caused less intraoperative bleeding due to coagulation of vessels by laser thermal effect [12], which helped in making the glandular resection easier and faster. Furthermore, vessel coagulation caused less post-operative ecchymosis [27].

In this study, our results using laser liposuction are comparable to other studies $[\mathbf{2 8 , 2 9 ]}$. It has many advantages; quick recovery time, dermal tightening, excellent patient's tolerance and relatively high satisfaction scores. 
Zocchi [22] developed ultrasound-assisted liposuction. Ultrasound-assisted liposuction turns electric energy into vibrations and causes thermal, cavitational, and mechanical effects that lead fat to fragment [30]. Ultrasound-assisted liposuction (VASER) also permitted rapid, efficient and controlled tissue removal, however, it carries the risk of thermal burns and requires larger incisions [31,32] which is comparable to our results in this study.

In this study we found that Ultrasound-assisted liposuction (VASER) group had a lower satisfaction score than laser group; although this was not statistically significant, yet it was clinically significant through the breast evaluation score. Moreover complications were relatively higher in the Ultrasound-assisted liposuction (VASER) group.

\section{Conclusion:}

Surgical excision of Gynecomatia grade II can be combined with either ND: YAG laser or Ultrasound-assisted liposuction (VASER) with comparable results. However, ND: YAG laser liposuction is more advantageous concerning the patients' satisfaction and post-operative complications.

\section{REFERENCES}

1- Lista F. and Ahmad J.: Gynecomastia. In: Spear SL, Willey S.C., Robb G.L.E., et al. (Eds.): Surgery of The Breast: Principles and Art (3rd Edn), Lippincott Williams \& Wilkins; Philadelphia, 1205-10, 2011.

2- Cohen I.K., Pozez A.L. and Mckeown J.E.: Gynecomastia. In E. Fl. Courtiss (Ed): Male Aesthetic Surgery. St. Louis: Mosby, 1991.

3- Yordanov Y., Shef A. and Hristoskova R.: Albena Fakirova Post-Traumatic Onset of Secondary Progression of Gynecomastia. Eur. J. Plast. Surg., 39 (5): 387-90, 2016.

4- Simon B.E., Hoffman S. and Kahn S.: Classification and surgical correction of gynecomastia. Plastic and Reconstructive Surgery, 51 (1): 48-52, 1973.

5- Rohrich R.J., Ha R.Y., Kenkel J.M. and Adams W.P.: Classification and Management of Gynecomastia: Defining the Role of Ultrasound-Assisted Liposuction. Plast. Reconstr. Surg., 111 (2): 909-23, 2003.

6- Adriana C. and Francesco M.: Algorithm for clinical evaluation and surgical treatment of gynecomastia. Journal Plastic, Reconstructive \& Aesthetic Surgery, 61: 4149, 2008.

7- American Society of Plastic Surgeons, 2017: Plastic surgery statistics report. Available at: https: //www. plasticsurgery. org/documents/News/Statistics/2017/plasticsurgery-statistics-full-report-2017.pdf. Accessed August 3, 2018.

8- Bembo S.A. and Carlson H.E.: Gynecomastia: Its Features, and When and How to Treat It. Cleveland Clinic Journal of Medicine, 71: 511-7, 2004.
9- Webster J.P.: Mastectomy for Gynecomastia Through a Semicircular Intra-areolar Incision. Ann. Surg., 124 (3): 557-75, 1946.

10- Teimourian B. and Perlman R.: Surgery for gynecomastia. Aesthetic Plast. Surg., 7 (3): 155-7, 1983.

11- Caridi and Robert C.: Defining the Aesthetic Units of the Male Chest and How They Relate to Gynecomastia Based on 635 Patients. Plastic and Reconstructive Surgery, 142 (4): 904-7, 2018.

12- Rho Y.K., Kim B.J., Kim M.N., Kang K.S. and Han H.J.: Laser lipolysis with pulsed 1064nm Nd:YAG laser for the treatment of gynecomastia. Int. J. Dermatol., 48 (12): 1353-9, 2009.

13- Zocchi M.L.: Ultrasonic liposculpturing. Aesthetic Plast. Surg., 16: 287-98, 1992.

14- Anderson R.C., Cunningham B., Tafesse E. and Lenderking W.R.: Validation of the breast evaluation questionnaire for use with breast surgery patients. Plast. Reconstr. Surg., 118 (3): 597-602, 2006.

15- Kasielska A. and Antoszewski B.: Effect of operative treatment on psychosocial problems of men with gynecomastia. Pol. Przegl. Chir., 83: 614-21, 2011.

16- Fagerlund A., Lewin R., Rufolo G., Elander A., Santanelli Di Pompeo F. and Selvaggi G.: Gynecomastia: A systematic review. J. Plast. Surg. Hand Surg., 49: 311-8, 2015.

17- Robert C. Caridi, M.D.: Defining the Aesthetic Units of the Male Chest and How They Relate to Gynecomastia Based on 635 Patients. Plast. Reconstr. Surg., 142: 904, 2018.

18- Hoyos A. and Perez M.: Dynamic- definition male pectoral reshaping and enhancement in slim athletic, obese and gynecomastia patients through selective fat removal and grafting. Aesthetic Plastic Surgery, 36 (5): 1066-77, 2012.

19- Teimourian B. and Pearlman R.: Surgery for gynecomastia. Aesthetic Plast. Surg., 7: 155-7, 1983.

20- Silberg B.N.: The technique of external ultrasound-assisted lipoplasty. Plast. Reconstr. Surg., 101 (2): 552, 1998.

21- Fodor P.B. and Vogt P.A.: Power-assisted lipoplasty (PAL): A clinical pilot study comparing PAL to traditional lipoplasty (TL). Aesthetic Plast. Surg., 23 (6): 379-85, 1999.

22- Zocchi M.L.: Ultrasonic liposculpturing. Aesthetic Plast. Surg., 16: 287-98, 1992.

23- Maxwell G.P. and Gingrass M.K.: Ultrasound-assisted lipoplasty: A clinical study of 250 consecutive patients. Plast. Reconstr. Surg., 101 (1): 189-202, 1998.

24- Zocchi M.L.: Ultrasonic-assisted lipectomy. Adv. Plast. Reconstr. Surg., 11: 197, 1995.

25- Apfelberg D.: Laser-assisted liposuction may benefit surgeons and subjects. Clin. Laser Mon., 10: 259, 1992.

26- McBean J. and Katz B.: Laser lipolysis: An update. J Clinical Aesth. Dermato., 4 (7): 25-34, 2011.

27- Yasser Abdallah Aboelatta and Mohammed Mahmoud Abdelaal: Comparison of laser-assisted liposuction and traditional liposuction combined with endoscopic surgical excision of grade II gynecomastia, Eur. J. Plast. Surg., 40: 541-8, 2017. 
28- Rho Y.K., Kim B.J., Kim M.N., Kang K.S. and Han H.J.: Laser lipolysis with pulsed $1064 \mathrm{~nm}$ Nd: YAG laser for the treatment of gynecomastia. Int. J. Dermatol., 48 (12): 1353-9, 61, 2009.

29- Trelles M.A., Mordon S.R., Bonanad E., et al.: Laserassisted lipolysis in the treatment of gynecomastia: A prospective study in 28 patients. Lasers Medical Science, 28 (2): 375-82, 2013.

30- Islam Abdelrahman, Ingrid Steinvall, Bassem Mossaad,
Folke Sjoberg and Moustafa Elmasry: Evaluation of Glandular Liposculpture as a Single Treatment for Grades I and II Gynaecomastia Aesth. Plast. Surg., 42: 1222-30, 2018.

31- Zukowski M.L. and Ash K.: Ultrasound-assisted lipoplasty learning curve. Aesthet. Surg. J., 18 (2): 104-10, 1998.

32- Illouz Y.G.: Complications of liposuction. Clin. Plast. Surg., 33 (1): 129-63, 2006. 